\title{
3D Meso-Mechanical Analysis Of Elastic Properties Of Concrete Materials
}

\author{
Zhi ZHANG ${ }^{1, a}$, Peibao $X U^{2, b}$ * \\ ${ }^{1}$ Anhui Nanxun Architectural \& Planning Design Institute CO.,LTD, Hefei, Anhui Province, 230088, \\ China \\ ${ }^{2}$ CAS Key Laboratory for Mechanical Behavior and Design of Materials, University of Science and \\ Technology of China, Hefei, Anhui Province, 230027, China \\ aemail: zz2000@126.com, bemail: pbxu@mail.ustc.edu.cn, *corresponding author
}

Keywords: 3D meso-mechanical model; Concrete; Interfacial transition zone; Elastic properties

\begin{abstract}
A 3D meso-mechanical model is introduced herein to estimate the elastic properties of concrete materials on the basis of the assumption that concrete can be considered as a three-phase material which contains cement mortar, aggregates and interfacial transition zone (ITZ). The influences of aggregate volume fraction and ITZ layer thickness on the elastic properties of concrete materials are considered in the present numerical study. It transpires that the elastic modulus increases very slightly with decreasing ITZ layer thickness and that the present model predictions are in good agreement with available experimental data and analytical results for elastic modulus. It also transpires that for a given aggregate size distribution and volume fraction the effect of aggregate shape is negligibly small in the numerical simulation.
\end{abstract}

\section{Introduction}

Concrete is a common composite material widely used in both defense and civil engineering because of its good mechanical properties relative to its cost. Therefore, it is extremely necessary to predict its elastic properties such as Young's modulus by means of the material natures of multiphase constituents of concrete [1]. As a matter of fact, great attention has been paid to the experimental and theoretical investigation of the quantitative relationships between the mesostructures and macroscopic physical properties of multiphase materials in the past few years [2] [5]. In the earlier meso-mechanical models as suggested in Refs.[4][6], the concrete was usually considered as a two-phase composite, which has a mortar matrix containing aggregates. Nonetheless, the theoretically predicted results for elastic modulus of concrete usually overestimate the values obtained from experiments [7][8], due to existence of a relatively porous ITZ layer between the aggregate particles and mortar matrix. In order to get more accurate results, Li et al. [5] developed a four-phase sphere model for predicting the elastic modulus of concrete and the model was treated as a three-phase material. However, the overlaps between the ITZ layers were not considered in calculating the ITZ volume fraction. Furthermore, the interaction of the three-phase constituents was not fully catered for in evaluating the elastic modulus of concrete. All these factors would contribute to the underestimation of the elastic modulus of concrete. To solve this problem, the numerical method was proposed [9]. At mesoscopic level, there existing many 3D meso-mechanical models have been developed [10] [13]. However, these meso-mechanical models do not contain ITZ layers. It should be mentioned here that even though the ITZ layer was considered in Ref.[11] the size of the specimen examined was very limited.

The objective of the present paper is to introduce a 3D meso-mechanical model to estimate the elastic properties of concrete, which can be used to simulate large scale concrete specimen. The numerical predictions are compared with experimental results as well as theoretical analysis. The effects of various parameters such as the thickness of ITZ layer, volume fraction of aggregates and aggregate shape are delineated and discussed. 


\section{Material Model And Numerical Model}

The behavior of concrete is complex due to different morphological features as well as deformation and failure mechanisms in its mesostructure. The material model developed in Ref.[14] and the numerical model presented in Ref. [15] for concrete will be adopted in the present simulations. It is assumed here that the ITZ layer is composed of the same material as that of the cement mortar matrix but with a lower strength [11][15] and that the aggregate behaves in an elastic manner.

It is well known that as a thin shell around aggregate particles, the typical thickness of an ITZ layer is $10 \sim 50 \mu \mathrm{m}$. In the present study, the ITZ layer is assumed to be homogeneous, which has a thickness of $30 \mu \mathrm{m}$. After many trials in simulations, the sizes of elements both for aggregate and cement mortar are the same, which are $0.5 \times 0.5 \times 0.5 \mathrm{~mm}$.

\section{Comparisons And Discussion}

The present numerical predictions are compared with some available experimental data as well as the existing analytical solutions and discussed.

Concrete With Spherical Aggregates. The present model is firstly verified against the compression experiments conducted on concrete with spherical aggregates reported by Zhou et al.[16]. In the simulations, the values of various parameters used in the simulations and analytical solutions are listed in Tables 1 and 2. The calculated results are listed in Table 3.

Table 1 Properties of cement mortar matrix and different aggregates [16].

\begin{tabular}{|c|c|c|c|c|c|c|}
\hline Material & $\begin{array}{l}\text { Shape of } \\
\text { aggregate }\end{array}$ & $\begin{array}{l}\text { Maximum } \\
\text { size } \\
(\mathrm{mm})\end{array}$ & $\begin{array}{c}\text { Volume } \\
\text { fraction } \\
(\%)\end{array}$ & $\begin{array}{c}\text { Young's } \\
\text { Modulus } \\
(\mathrm{GPa})\end{array}$ & $\begin{array}{l}\text { Poisson's } \\
\quad \text { ratio }\end{array}$ & $\begin{array}{l}\text { Density } \\
\left(\mathrm{kg} / \mathrm{m}^{3}\right)\end{array}$ \\
\hline Cement mortar & - & - & - & 40.8 & 0.21 & 2290 \\
\hline Limestone & Angular & 10 & \multirow{4}{*}{42.5} & 56 & 0.27 & 2640 \\
\hline Gravel & Rounded & 10 & & 54 & \multirow{2}{*}{$\begin{array}{l}0.21 \\
0.25\end{array}$} & 2570 \\
\hline Glass & Spherical & 10 & & 72 & & 2520 \\
\hline Steel & Spherical & 3 & & 210 & 0.28 & 7850 \\
\hline Parameters & Mortar & \multicolumn{2}{|c|}{ ITZ } & Parameters & Mortar & ITZ \\
\hline$\rho_{0}\left(\mathrm{~kg} / \mathrm{m}^{3}\right)$ & 2290 & \multicolumn{2}{|c|}{1800} & $n$ & 3 & 3 \\
\hline$\rho_{s 0}\left(\mathrm{~kg} / \mathrm{m}^{3}\right)$ & 2680 & \multicolumn{2}{|c|}{2680} & $G(\mathrm{GPa})$ & 16.9 & 9.4 \\
\hline$p_{\text {crush }}(\mathrm{MPa})$ & 30.3 & \multicolumn{2}{|c|}{18.2} & $f_{c}^{\prime}(\mathrm{MPa})$ & 91 & $\begin{array}{c}54 . \\
6\end{array}$ \\
\hline$p_{\text {lock }}(\mathrm{GPa})$ & 3 & \multicolumn{2}{|c|}{3} & $f_{t}(\mathrm{MPa})$ & 5.2 & 3.1 \\
\hline$K_{1}(\mathrm{GPa})$ & 23.4 & \multicolumn{2}{|c|}{20.4} & B & 1.1 & 1.1 \\
\hline$K_{2}(\mathrm{GPa})$ & 30 & 30 & & $N$ & 0.6 & 0.6 \\
\hline$K_{3}(\mathrm{GPa})$ & 10 & 10 & & & & \\
\hline & & & $\operatorname{Pr}$ & icted $E_{\text {eff }}(\mathrm{GP}$ & ) & \\
\hline aggregate & $\begin{array}{l}\text { Measured } E_{\text {eff }} \\
\qquad(\mathrm{GPa})\end{array}$ & Voigt's model & Reuss' $n$ & $\begin{array}{r}\text { An } \\
\text { solu }\end{array}$ & $\begin{array}{l}\text { ytical } \\
\text { on [17] }\end{array}$ & $\begin{array}{l}\text { Present } \\
\text { model }\end{array}$ \\
\hline Limestone & 49.5 & 47.2 & 46.1 & & 6.5 & 46.9 \\
\hline Gravel & 51.3 & 46.4 & 45.5 & & 5.7 & 46.1 \\
\hline Glass & 52.8 & 54.0 & 50.0 & & 1.2 & 51.1 \\
\hline Steel & 69.9 & 112.8 & 62.0 & & 8.2 & 68.8 \\
\hline
\end{tabular}

* $E_{\text {eff }}$ is equivalent elastic modulus of concrete.

Table 3 shows comparison between the present model predictions and the experimental data for concrete containing aggregates with different material properties reported by Zhou et al.[16]. Also shown in Table 3 are the analytical solutions from the models of Voigt and Reuss [16] and the model 
suggested in Ref. [17]. As can be seen from Table 3 that both the simulation results and the analytical solutions proposed in Ref. [17] are in good agreement with the test data for elastic modulus of concretes with glass and steel aggregates except for limestone and gravel aggregates where the experimentally obtained elastic moduli are outside the upper and lower bounds given by Voigt's and Reuss' models, respectively. It may be due to the fact that the elastic moduli for limestone and gravel are underestimated by the empirical formula used in Ref. [16]. Nonetheless, for concretes containing limestone and gravel aggregates the present numerical simulations are similar to the analytical solutions predicted from the model presented in Ref. [17] as can be seen from Table 3.

It should be mentioned here that the experimental results reported by Zhou et al. were only for single-graded concrete which means the aggregates used in each concrete specimen are of the same size. Due to paucity of the test results for concretes containing spherical aggregates of different sizes the present numerical simulations are compared with the analytical solutions of the model suggested by Li and Zheng[17] for fully-graded concrete containing spherical glass aggregates of different sizes in Fig.1. Since there is only a kind of aggregate with diameter of $10 \mathrm{~mm}$, the largest aggregate fraction which can be achieved in the numerical simulation is $49 \%$. Even so, it can be seen from the figure that good agreement is obtained for a range of aggregate volume fraction $\left(\mathrm{V}_{\mathrm{a}}\right)$.

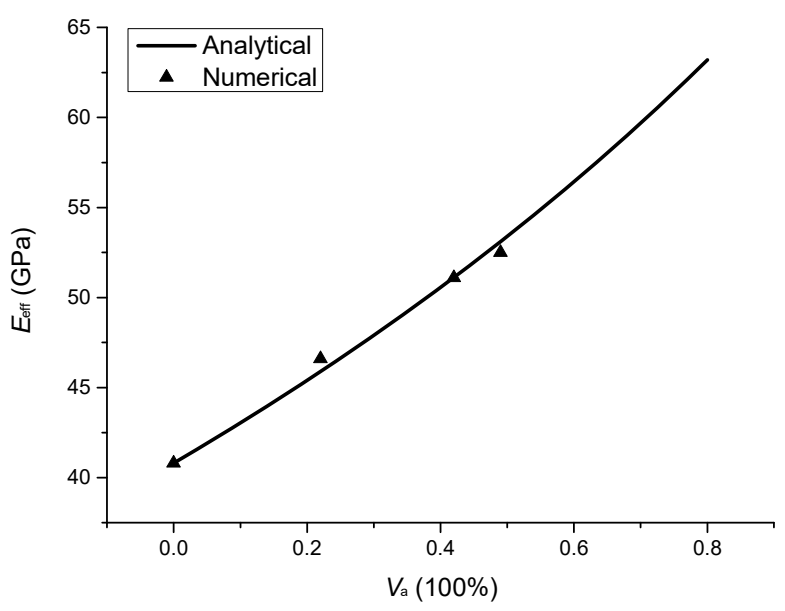

Fig. 1. Comparison of the present numerical results with the analytical solutions [17].

In order to make an assessment about the influence of the thickness of ITZ layer on the elastic properties (modulus) of concrete numerical simulations are performed with different ITZ thicknesses of $10 \mu \mathrm{m}, 30 \mu \mathrm{m}$ and $50 \mu \mathrm{m}$. As shown in Fig.2, the numerical simulation results are similar to those of analytical solution, that is, the elastic modulus of concrete is found to increase slightly with decreasing ITZ thickness. In which the symbol $E_{\mathrm{m}}$ is the elastic modulus of cement mortar.

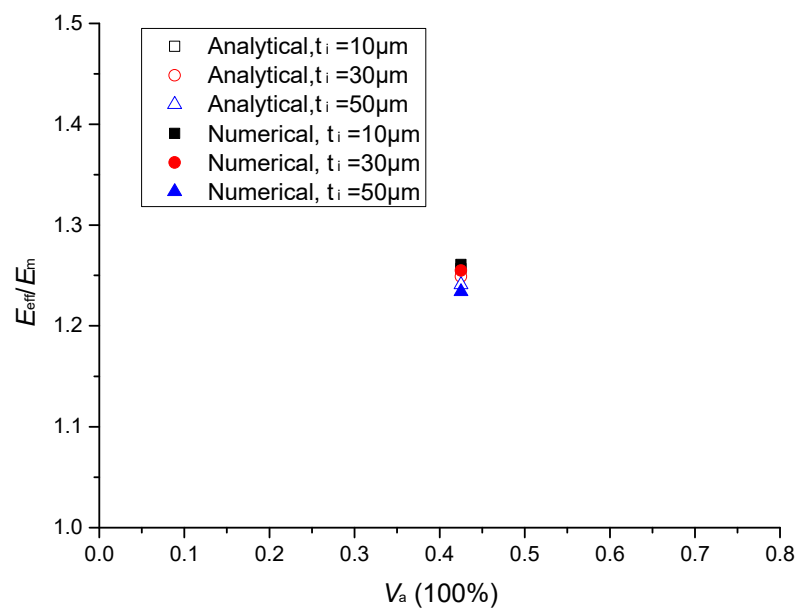


Fig. 2. The effect of ITZ layers on prediction for elastic modulus of concrete.

Concrete With Irregular Aggregates.To a first approximation, the present model may be applicable to concretes with irregular aggregates. Fig.3 shows comparison between the present numerical simulations and the tensile experiment reported by Stock et al. [18]. In the numerical simulations, Fuller's curve [5][10] is adopted for aggregate gradation of concrete. The values of various parameters used in the simulations for the cement mortar matrix and the ITZ layers are listed in Table 4. In the experiments [18], the largest aggregate size was $19 \mathrm{~mm}$. In the present simulations the sizes of the coarse aggregates range from $2.4 \mathrm{~mm}$ to $19 \mathrm{~mm}$. The aggregate elastic modulus was $74.5 \mathrm{GPa}$ and the aggregate volume fractions were $0.2,0.4,0.6$ and 0.8 , respectively.

Table 4 Material parameters of cement mortar and ITZ layer [15][18].

\begin{tabular}{lcclcc}
\hline \multicolumn{1}{c}{ Parameters } & Mortar & ITZ & Parameters & Mortar & ITZ \\
\hline$\rho_{0}\left(\mathrm{~kg} / \mathrm{m}^{3}\right)$ & 2190 & 1800 & $n$ & 3 & 3 \\
$\rho_{s 0}\left(\mathrm{~kg} / \mathrm{m}^{3}\right)$ & 2680 & 2680 & $G(\mathrm{GPa})$ & 4.6 & 2.7 \\
$p_{\text {crush }}(\mathrm{MPa})$ & 11.5 & 6.9 & $f_{c}^{\prime}(\mathrm{MPa})$ & 34.5 & 20.7 \\
$p_{\text {lock }}(\mathrm{GPa})$ & 3 & 3 & $f_{t}(\mathrm{MPa})$ & 2.3 & 1.4 \\
$K_{1}(\mathrm{GPa})$ & 7.7 & 5.8 & $B$ & 1.8 & 1.8 \\
$K_{2}(\mathrm{GPa})$ & 30 & 30 & $N$ & 0.5 & 0.5 \\
$K_{3}(\mathrm{GPa})$ & 10 & 10 & & & \\
\hline
\end{tabular}

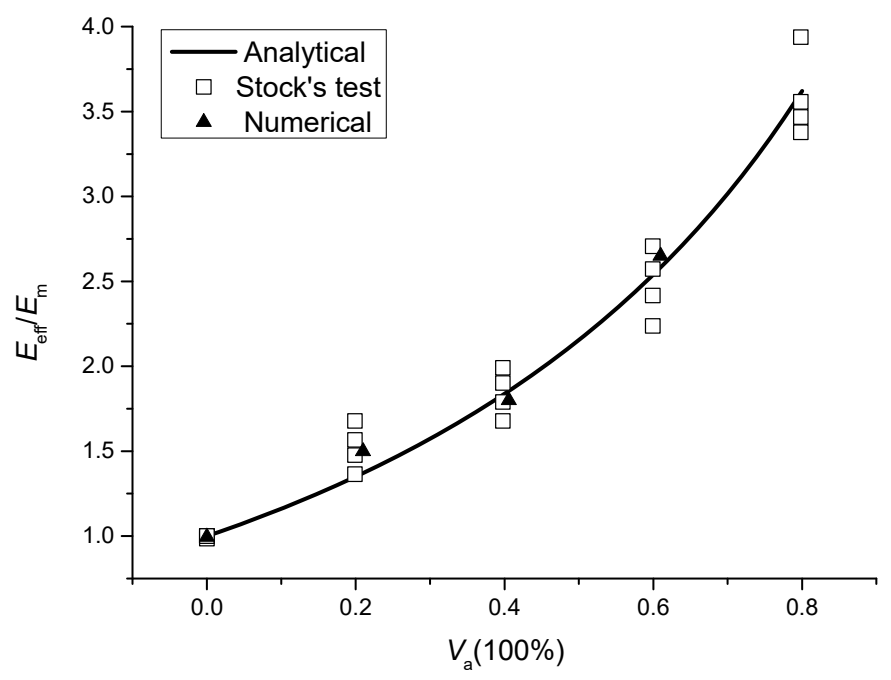

Fig. 3. Comparison of the present numerical results with the analytical solutions and the experimental results [18].

It can be seen from Fig. 3 that the present numerical model produces similar results to those of the analytical model [17], which are both in good agreement with the experimental data [18]. This implies that the elastic properties such as Young's modulus are strongly dependent on the aggregate volume fraction and size distribution and weakly dependent on the shapes of aggregates. In other words, for a concrete once aggregate volume fraction and size distribution is given its elastic properties are also determined irrespective of the shapes of aggregates. Hence, the 3D meso-mechanical model developed for concretes with spherical aggregates can be applied to evaluate the elastic properties of concretes with irregular aggregates provided that the aggregate volume fraction and size distribution are kept the same. 


\section{Conclusions}

The 3D meso-mechanical model has been introduced to predict the elastic properties of concrete materials, which has successfully overcome the difficulty of simulating the very thin ITZ layer. The influences of aggregate volume fraction and ITZ layer thickness on the elastic properties of concrete materials are considered in the present numerical study. The elastic modulus of concrete is found to increase with increasing both the volume fraction and the modulus of aggregate. It is also found that it increases slightly with decreasing ITZ thickness and, hence, a thickness of $30 \mu \mathrm{m}$ for ITZ layer as suggested in the literature is recommended in the numerical simulations. For a given aggregate size distribution and volume fraction the effect of aggregate shape on the elastic modulus of concrete is negligibly small.

\section{References}

[1] J.J. Zheng, C.Q. Li, X.Z. Zhou, An analytical method for prediction of the elastic modulus of concrete, Magazine of Concrete Research. 58(10) (2006) 665-673.

[2] J.S. Dolado, K. Van Breugel, Recent advances in modeling for cementitious materials, Cement and Concrete Research. 41(7) (2011) 711-726.

[3] G. Ramesh, E.D. Sotelino, W.F. Chen, Effect of transition zone on elastic moduli of concrete materials, Cement and Concrete Research. 26(4) (1996) 611-622.

[4] J. Vilardell, A. Aguado, L. Agullo, et al., Estimation of the modulus of elasticity for dam concrete, Cement and Concrete Research. 28(1) (1998) 93-101.

[5] G. Li, Y. Zhao, S.S. Pang, Four-phase sphere modeling of effective bulk modulus of concrete, Cement and Concrete Research. 29(6) (1999) 839-845.

[6] İ.B. Topçu, T. Bilir, A.R. Boğa, Estimation of the modulus of elasticity of slag concrete by using composite material models, Construction and Building Materials. 24(5) (2010) 741-748.

[7] Z. Hashin, S. Shtrikman, A variational approach to the theory of the elastic behaviour of multiphase materials, Journal of the Mechanics and Physics of Solids. 11(2) (1963) 127-140.

[8] P. Simeonov, S. Ahmad, Effect of transition zone on the elastic behavior of cement-based composites, Cement and Concrete Research. 25(1) (1995) 165-176.

[9] C.Q. Li, J.J. Zheng, X.Z. Zhou, et al., A numerical method for the prediction of elastic modulus of concrete, Magazine of Concrete Research. 55(6) (2003) 497-505.

[10]P. Wriggers, S.O. Moftah, Mesoscale models for concrete: Homogenisation and damage behavior, Finite elements in analysis and design. 42(7) (2006) 623-636.

[11]Y. Hao, H. Hao, X.H. Zhang, Numerical analysis of concrete material properties at high strain rate under direct tension, International Journal of Impact Engineering. 39(1) (2012) 51-62.

[12]Q. Fang, J. Zhang, 3D numerical modeling of projectile penetration into rock-rubble overlays accounting for random distribution of rock-rubble, International Journal of Impact Engineering. 63 (2014) 118-128.

[13]B. Erzar, P. Forquin, Experiments and mesoscopic modelling of dynamic testing of concrete, Mechanics of materials. 43(9) (2011) 505-527.

[14]H. Xu, H.M. Wen, A computational constitutive model for concrete subjected to dynamic loadings. International Journal of Impact Engineering. 91 (2016) 116-125.

[15]P.B. Xu, H. Xu, H.M. Wen, 3D meso-mechanical modelling of concrete spall tests. International Journal of Impact Engineering. 97 ( 2016) 46-56. 
[16]F.P. Zhou, F.D. Lydon, B.I.G. Barr, Effect of coarse aggregate on elastic modulus and compressive strength of high performance concrete, Cement and Concrete Research. 25(1) (1995) 177-186.

[17]C.Q. Li, J.J. Zheng, Closed-form solution for predicting elastic modulus of concrete, ACI Materials Journal. 104(5) (2007) 539-546.

[18]A.F. Stock, D.J. Hannantt, R.I.T. Williams, The effect of aggregate concentration upon the strength and modulus of elasticity of concrete, Magazine of Concrete Research. 31(109) (1979) 225-234. 